\title{
Reduction Ratios of Rodent Active Burrows after using Aluminum Phosphate (Fumigation) under Field Conditions
}

\author{
Abd El-Aleem S.S.Desoky ${ }^{1}$; K. H. Abdel-Gwad ${ }^{2}$; A. Maher Ali ${ }^{2}$, A. A. Nafady \\ ${ }^{1}$ Plant protection Department (Zoology), Faculty of Agriculture, Sohag University, Egypt \\ ${ }^{2}$ Plant Protection Department, Faculty of Agriculture, Assiut University, Egypt \\ ${ }^{3}$ Pathology Department, Faculty of Veterinary Medicine, Assiut University, Egypt \\ abdelalem2011@yahoo.com
}

\begin{abstract}
The present work aim to the evaluation of using aluminum phosphate 33\% (fumigation) against reduction of rodent active burrows under field conditions. Results show that the active burrows of rodent were decreased when used Aluminum phosphate fumigation (64.19\%) after one month as compared to the normal burrows.
\end{abstract}

Keywords: aluminum phosphate, fumigation, reduction, rodent active burrows, normal burrows.

\section{INTRODUCTION}

Rodenticides, in many situations, are the most practical and effective way to reduce a large, widespread rodent population. There are two general classes of oral rodenticides. Acute rodenticides (including zinc phosphide and strychnine) usually kill with a single feeding. In contrast, chronic or multiple-feeding rodenticides (including warfarin, diphacinone, and chlorophacinone) usually require a period (days) of feeding before killing. The distinction has become somewhat blurred because the anticoagulant group includes first generation (examples given) and second generation (bromadiolone, brodifacoum, difethialone) anticoagulants. Second generation anticoagulants are very toxic and can usually kill within several days of a single feeding. These materials are generally not available for field application. Use patterns generally allow rodents to feed continuously at bait stations or on bait blocks, however, so that second generation materials offer no practical advantage in many situations. An additional group of rodent toxicants includes the fumigants (e.g., gas cartridges, aluminum phosphide, methyl bromide) which are used in building fumigation or in burrow systems that are closed after application (Khan et al., 1998; Witmer, 1999 and Desoky, 2014).

\section{MATERIALS AND METHODS}

The present study was conducted in the farm animals of the Faculty of Agriculture, Assiut University, Egypt during 2010 year. Aluminum phosphide was evaluated against rodents under field conditions based on reduction in the active burrows. In three areas for each treatment, 20 active burrows were marked. A distance of $200 \mathrm{~m}$ was left between each treatment and the others. The fumigation tablets were distributed into the active burrows. On the other hand, 20 active burrows were marked as a control; the percentage of rodent active burrows was recorded two times every week. The experimental lasted for one month.

\section{RESULTS AND DISCUSSION}

Reduction of rodent active burrows after using aluminum phosphate 33\% (fumigation) during one month under field conditions were less gradually after so, the activity of the rodent active burrow increased gradually to attain by mean $64.19 \%$ after month (Fig.1). Aluminum phosphate can be used in rodent control (Carl Snider, 1983).Aluminum phosphide is a new burrowing rodent fumigant in USA. It reacts with water vapor to produce hydrogen phosphide gas. Hydrogen phosphide is a very toxic gas, however, several characteristics of the product and use pattern give most commercial formulations a low user hazard when used by trained applicators in accordance with label instructions. It is efficacious when used in many situations against several burrowing rodent species, but will not be effective in all situations. 
Several factors to consider are burrow temperature, burrow humidity, burrow length and configuration, soil porosity, wind speed and direction, and species specific behavior characteristics. It is particularly desirable to use as a clean-up after a baiting program. Also, it can be used throughout most of the year. The user should read the label carefully to determine all endangered species precautions. Hydrogen phosphide has no secondary hazard although burrow dwelling non-target animals will probably be killed.

\section{CONClusion}

In conclusion, the recommended procedure for rodent control is applying aluminum phosphate followed by anticoagulants twice annually seems to be satisfactory to apply within active burrows. However, it is rather important to give all possible attention to environmental sanitation. At the same time, type of applied anticoagulant should be changed upon appearance signs of resistance of rodents under control to such product). The result was obtained by Shehab et al. (2000); Yaghoobi-Ershadi et al.(2000) and Witmer et al. (1995).

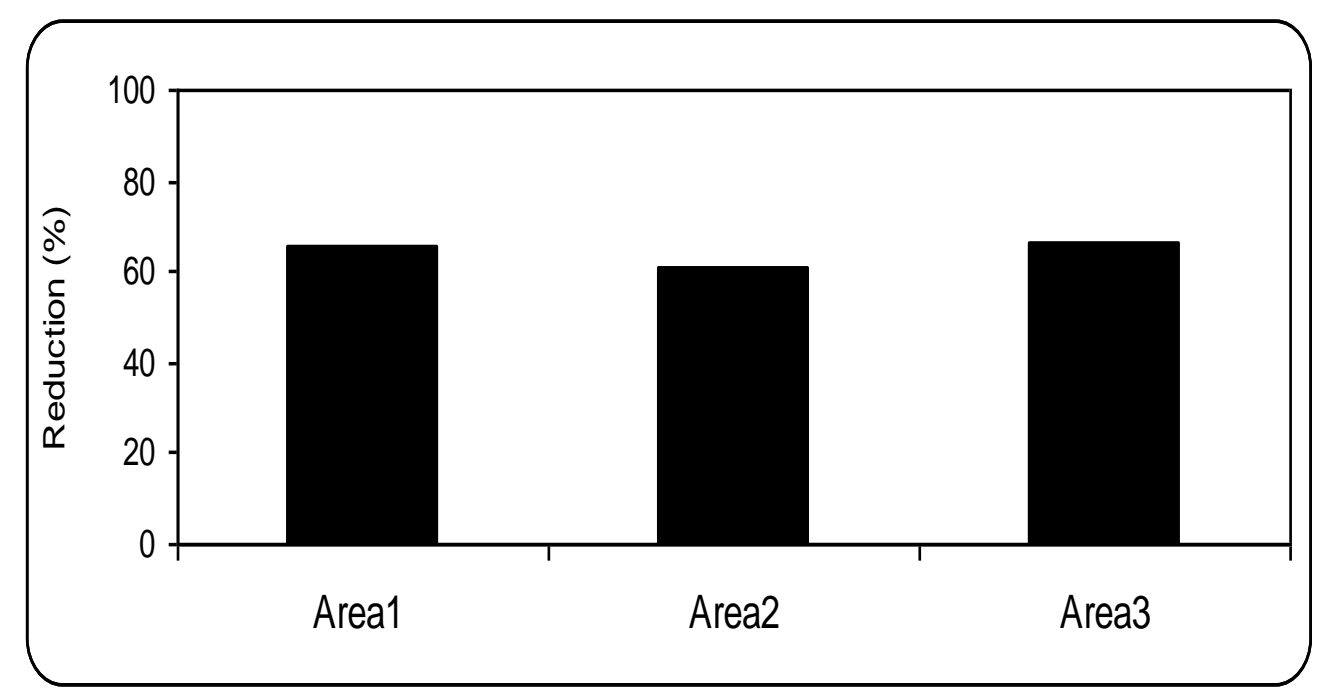

Fig1. Reduction ratios of rodent active burrows after using aluminum phosphate 33\% (fumigation) during one month under field conditions in animal-farm, of Fac. Agric., Assiut University

\section{REFERENCES}

Desoky, A.S.S (2014). Review Strategies of Rodent Control Methods at Airports, Global Journal of Science Frontier Research: C Biological ScienceVolume 14 Issue 2 Version 1.0.

Carl Snider (1983). Use of Aluminum Phosphide Fumigants For Burrowing Rodent Control. Wildlife Damage Management, Internet Center for Great Plains Wildlife Damage Control Workshop Proceedings. 57-59.

Khan, A. A.; S. Munir; A. R. Shakoor (1998). Development of under-ground baiting technique for control of rats in rice fields in Pakistan. Int. Biodeterioation.42: 129-134 .

Shehab, A.; F. Samara and A. Daoud (2000). The effectiveness of different bait bases of zinc phosphide in controlling social voles Microtus socialis in the middle of Syria. The $2^{\text {nd }}$ Scientific Conference of Agricultural Sciences, Assiut, Oct.

Witmer, G. W.; M. W. Fall and L. A. Fiedler (1995). Rodent control, research needs, and technology transfer. International wildlife management congress, 16-26.

Witmer, G. (1999). Field efficacy of "Zinc Phosphide Concentrate" (EPA Reg. No. 56228-6) on rolled oats for controlling deer mice (Peromyscus spp.) infields around structures. Unpublished Report to U.S. Environmental Protection Agency, Washington, D.C. USDA, Animal and Plant Health Inspection Service, Wildlife Services, National Wildlife Research Center, Fort Collins, CO, USA.

Yaghoobi-Ershadi, M. R.; A. A. Akhavan; A. R. Z. Ramazani; E. Javadian and M. M. Emami (2000). Field trial for the control of zoonotic cutaneous leishmaniosis in Badrood, Iran. Ann., Saudi Medicine., 382-392. 